\title{
Editorial: Time for a fresh approach, for a (not so) new journal, a journal for new times
}

In our inaugural editorial for the Journal of Organizational Ethnography: Time for a new journal, a journal for new times, we set out with the ambition to support an emerging community of ethnographers gathered around the Annual Ethnography Symposium and to reflect the symposium in textual form. As editors, we have not been prolific in our editorial comments, preferring a supporting rather than starring role, but as we approach the milestone, it is perhaps long since time that we thanked a few people who have been instrumental in the journal's first decade. First, we thank our authors and guest editors. Many of you have understood what we are trying to do and have shared and supported the endeavour. We hope you have experienced our editorial approach as one intended to encourage and develop ideas, papers and ethnographic practice and that through these pages, digital or paper, you have succeeded in connecting with a supportive and knowledgeable audience.

Second, of course, we should thank our reviewers. They have enthusiastically taken our lead in respecting submissions on their own terms and been overwhelmingly helpful and constructive in their approach to this nonremunerated, undervalued bedrock upon which academic publishing is built.

One of the absolute joys of working through the Journal of Organizational Ethnography (JOE) is the sheer variety and multi-disciplinarity of the work we have attracted. This has posed a very particular challenge in having a wide enough network to secure reviewers with relevant expertise; therefore, we would particularly note a few stalwarts who have stepped up when we have struggled. Without such reviewers, we would be lost.

Third, there is a special category of those who have contributed. We are thinking of some colleagues who have offered advice to authors of papers that were not appropriate to JOE, but that merited some attention and encouragement. This has fallen largely on editors, but occasionally others have offered their advice where their expertise was required. A particular word of thanks in that regard goes to Rebecca Wood of the University of East London.

Fourth, and finally, thanks to our readers. The regular updates we see from the publishers indicate a global reach but with particular nodes at Copenhagen Business School, Aarhus University and Vrije Universiteit Amsterdam. Thank you.

And so to an announcement. After ten years, it is perhaps time for a new direction. We have begun talking about handing over the editorial duties to new colleagues. Dr Bagga Bjerge from Aarhus University and Dr Hugo Valenzuela from Universitat Autònoma de Barcelona joined recently as associate editors. However, we would like to extend an open invitation to anyone interested in taking on editorial duties with JOE and who would like to have a conversation about what that might entail to please contact us as the editors.

May, 2021

Matthew Brannan, Manuela Nocker and Mike Rowe

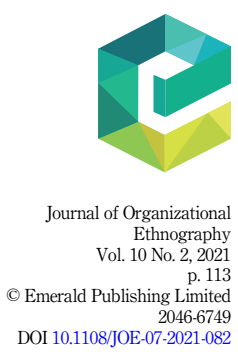

